\title{
TYRP1 mRNA level is stable and MITF-M-independent in drug-naïve, vemurafenib- and trametinib-resistant $\mathrm{BRAF}^{\mathrm{V} 600 \mathrm{E}}$ melanoma cells
}

\author{
Mariusz L. Hartman ${ }^{1} \cdot$ Malgorzata Czyz $^{1}$ (D)
}

Received: 30 April 2019 / Revised: 20 September 2019 / Accepted: 3 October 2019 / Published online: 17 October 2019

(c) The Author(s) 2019

\begin{abstract}
TYRP1 mRNA is of interest due to its potential non-coding role as a sponge sequestering tumor-suppressive miRs in melanoma. To our knowledge, there is no report on changes in TYRP1 expression in melanomas after development of resistance to targeted therapies. We used patient-derived drug-naïve $\mathrm{RAS}^{\mathrm{Q} 61 \mathrm{R}}$ and $\mathrm{BRAF}^{\mathrm{V} 600 \mathrm{E}}$ melanoma cell lines. In $\mathrm{BRAF}^{\mathrm{V} 600 \mathrm{E}}$ melanoma cells, resistance to vemurafenib and trametinib was developed. A time-lapse fluorescence microscope was used to rate proliferation, qRT-PCR and Western blotting were used to assess TYRP1 expression and MITF-M level and activity. A high TYRP1 protein level in RAS ${ }^{\text {Q61R }}$ cells corresponded with high TYRP1 mRNA level, whereas undetectable TYRP1 protein in $\mathrm{BRAF}^{\mathrm{V} 600 \mathrm{E}}$ cells was accompanied by medium mRNA level, also in cells carrying NF1 ${ }^{\mathrm{R} 135 \mathrm{~W}}$ variant in addition. TYRP1 expression was MITF-M-independent, since similar transcript status was found in MITF-M ${ }^{\text {high }}$ and MITF-M ${ }^{\text {low }}$ cells. For the first time, we showed that TYRP1 expression remained unaltered in melanoma cells that became resistant to vemurafenib or trametinib, including those cells losing MITF-M. Also drug discontinuation in resistant cells did not substantially affect TYRP 1 expression. To verify in vitro results, publicly available microarray data were analyzed. TYRP1 transcript levels stay unaltered in the majority of paired melanoma samples from patients before treatment and after relapse caused by resistance to targeted therapies. As TYRP1 mRNA level remains unaltered in melanoma cells during development of resistance to vemurafenib or trametinib, therapies developed to terminate a sponge activity of TYRP1 transcript may be extended to patients that relapse with resistant disease.
\end{abstract}

Keywords TYRP1 $\cdot$ MITF $\cdot \operatorname{miR}$ sponge $\cdot$ Melanoma $\cdot$ Resistance $\cdot$ Targeted therapy

\section{Introduction}

Melanoma is the most deadly form of skin cancer. One of the important factors determining melanoma risk is the epidermal melanin content [45]. TYRP1 (tyrosinase-related protein 1) and two other enzymes, tyrosinase and TYRP2, are active in the melanin production. TYRP1 is a marker of melanocyte differentiation but it is also involved in the survival response to oxidative stress [16]. TYRP1 protein expression is reduced in invasive melanomas [4], while TYRP1 mRNA level is increased [28]. TYRP1 mRNA, in addition to the protein-coding function, has been recognized

Malgorzata Czyz

malgorzata.czyz@umed.lodz.pl

1 Department of Molecular Biology of Cancer, Medical University of Lodz, 6/8 Mazowiecka Street, 92-215 Lodz, Poland as contributing to regulation of gene expression by serving as an endogenous miR sponge [17].

In melanocytes, expression of about one hundred genes, including TYRP1, is microphthalmia-associated transcription factor (MITF)-dependent [6, 14, 18, 33, 42]. The M isoform of MITF (MITF-M) is one of the major players affecting melanoma phenotype $[5,20,26]$. Its regulation is complex and involves microenvironmental components [20, 24]. A high MITF-M level is connected with differentiation, a medium level with proliferation, whereas a low level is associated with an invasive and stem-like phenotype [5, 20, 26]. MITF-M also plays a prosurvival role in melanoma cells [21]. The MITF level is enhanced in $\mathrm{BRAF}^{\mathrm{V} 600 \mathrm{E}}$ melanoma cells upon acute exposure to vemurafenib [35], and MITF inhibition increases sensitivity of cells to this inhibitor [1]. On the contrary, the MITF level and expression of several MITF-dependent genes are markedly reduced in vemurafenib-resistant melanomas resulting in more primitive phenotypes of melanoma cells [40]. Reduced MITF expression 
followed by the suppression of MITF-dependent pigmentation program were recently reported not only in vemurafenib-resistant cell lines but also in most of trametinibresistant cell lines [8].

Therefore, we found it interesting to investigate changes of TYRP1 transcript levels in relation to MITF level and its activity shown as transcript levels of other MITF-dependent genes, SLC45A2, BIRC7/livin and BCL2A1, during the development of drug resistance. SLC45A2 (solute carrier family 45), together with TYRPI belongs to pigmentationrelated genes [44], whereas $B I R C 7$ (baculoviral IAP repeatcontaining 7) and BCL2Al (BCL2-related protein A1) encode prosurvival proteins $[9,32]$. We assumed that diminution of MITF-M level during development of resistance would be accompanied with reduced expression of MITF-Mdependent genes. The question was whether TYRP1 mRNA would also be reduced. The answer is important as reduced level of the TYRP1 transcript may limit its function as a miR sponge in resistant cells. We performed our study in drug-naïve MITF-M ${ }^{\text {high }}$ and MITF-M ${ }^{\text {low }}$ patient-derived melanoma cell lines and their vemurafenib- or trametinibresistant counterparts, also subjected to drug discontinuation ('drug holiday').

\section{Materials and methods}

\section{Drugs}

Vemurafenib and trametinib were purchased from Selleck Chemicals LLC (Houston, TX, USA).

\section{Melanoma cell line generation and culture}

Tumor tissues from drug-naïve melanoma patients were processed as described previously [22]. The study was approved by Ethical Commission of Medical University of Lodz and informed consent was obtained from all individual participants included in the study. Melanoma cells were maintained in culture as described previously [37]. To generate lines resistant to vemurafenib or trametinib, cells were cultured for 4-5 months with increasing concentrations of drugs, from 1 to $10 \mu \mathrm{M}$ and from 1 to $50 \mathrm{nM}$, respectively. For 'drug holiday' experiments, the drug was removed from the medium for 10 days.

\section{A time-lapse fluorescence microscopy}

Melanoma cells were grown in 96-well plates at $8 \times 10^{3}$ cells/ well. For cell proliferation, a time-lapse fluorescence microscope system (IncuCyte, Essen Bioscience) was used. The data were analyzed using the IncuCyte Zoom original software. Proliferation was assessed as changes in the area occupied by cells ( $\%$ of confluence) over time. It was expressed as $\%$ of confluence of cells at indicated time divided by $\%$ of confluence of cells at time 0 .

\section{RNA isolation and quantitative real-time PCR (qRT-PCR)}

Extraction of RNA, cDNA synthesis and qRT-PCR were described previously [22]. Primer sequences are shown in Table 1. To calculate the relative normalized expression of target genes, a reference gene RPS 17 and a mathematical model including an efficiency correction were applied.

\section{Cell lysate preparation and Western blotting}

Cell lysate preparation and Western blotting were described elsewhere [34]. Antibodies detecting MITF (Cell Signaling, Danvers, MA, USA), TYRP1, GAPDH (Santa Cruz Biotechnology, Santa Cruz, CA, USA), or $\beta$-actin (Sigma-Aldrich) were used followed by binding of HRP-conjugated antimouse/anti-rabbit antibodies (Santa Cruz Biotechnology).
Table 1 Primer sequences, forward $(\mathrm{F})$ and reverse $(\mathrm{R})$ used in the qRT-PCR experiments

\begin{tabular}{|c|c|c|c|}
\hline Gene & Sequence & $T_{\mathrm{M}}\left({ }^{\circ} \mathrm{C}\right)$ & Amplicon (bp) \\
\hline \multirow[t]{2}{*}{$B C L 2 A 1$} & F: GGATAAGGCAAAACGGAGGCTG & 62 & 183 \\
\hline & R: CAGTATTGCTTCAGGAGAGATAGC & 59 & \\
\hline \multirow[t]{2}{*}{$B I R C 7$} & F: TGTCCACAGTGTGCAGGAGACT & 64 & 127 \\
\hline & R: GGCACTTTCAGACTGGACCTCT & 64 & \\
\hline \multirow[t]{2}{*}{ MITF-M } & F: GCTGGAAATGCTAGAATA & 57 & 379 \\
\hline & R: TTCCAGGCTGATGATGTC & 59 & \\
\hline \multirow[t]{2}{*}{ RPS17 } & F: AATCTCCTGATCCAAGGCTG & 60 & 142 \\
\hline & R: CAAGATAGCAGGTTATGTCACG & 58 & \\
\hline \multirow[t]{2}{*}{ SLC45A2 } & F: CTTTGCATCAGCCACCTCATTGG & 65 & 153 \\
\hline & R: TCCAACCTCGACTCCTCTTTCG & 64 & \\
\hline \multirow[t]{2}{*}{ TYRP1 } & F: GAAAAGAGCCACTTTGTCAGGG & 62 & 104 \\
\hline & R: CCATCTGGTCCCAGTATGTCT & 61 & \\
\hline
\end{tabular}


The proteins were visualized using ChemiDoc Imaging System (Bio-Rad).

\section{Analysis of TYRP1 expression reported in data sets from the Gene Expression Omnibus (GEO) database}

The publicly available microarray data sets (accession numbers: GSE77940, GSE61992, GSE50509 and GSE99898) were downloaded from the GEO database (https://www.ncb. nlm.nih.gov). The TYRP1 expression profiles were developed from paired BRAF ${ }^{\mathrm{V} 600}$ melanoma samples from 31 patients in pretreatment stage and after relapse due to development of resistance to either vemurafenib or dabrafenib, and from paired melanoma samples from 17 patients before treatment and after relapse due to resistance to a combination of dabrafenib and trametinib. Gene expression values were $\log _{2}$ transformed.

\section{Statistical analysis}

Graphs represent mean \pm SD of three biological replicates. Student's $t$ test was used to determine significant differences between the mean values. The difference was considered significant if $p \leq 0.05$.

\section{Results}

\section{TYRP1 expression in patient-derived melanoma cell lines is MITF-M-independent}

Eight patient-derived melanoma cell lines were used initially in this study. Six of them harbor a mutation leading to $\mathrm{BRAF}^{\mathrm{V} 600 \mathrm{E}}$, and two of them harbor a RAS variant, either $\mathrm{NRAS}^{\mathrm{Q} 61 \mathrm{R}}$ (DMBC22 cell line) or HRAS ${ }^{\mathrm{Q} 61 \mathrm{R}}$ (DMBC17 cell line) [23]. DMBC28 cell line harbors an $\mathrm{NF}^{\mathrm{R} 135 \mathrm{~W}}$ variant in addition to $\mathrm{BRAF}^{\mathrm{V} 600 \mathrm{E}}$ alteration [23]. They exerted different proliferation rates as assessed by time-lapse fluorescence microscopy (Fig. 1a). TYRP1 expression was MITF$\mathrm{M}$-independent, since in all $\mathrm{BRAF}^{\mathrm{V} 600 \mathrm{E}}$ melanoma cell lines, both MITF-M $\mathrm{M}^{\text {high }}$ and MITF-M ${ }^{\text {low }}$, levels of TYRP1 transcript were similar (Fig. 1b). Interestingly, TYRP1 mRNA levels in cells carrying mutation either in NRAS or in HRAS were much higher than in $\mathrm{BRAF}^{\mathrm{V} 600 \mathrm{E}}$ melanoma cells. This was
A

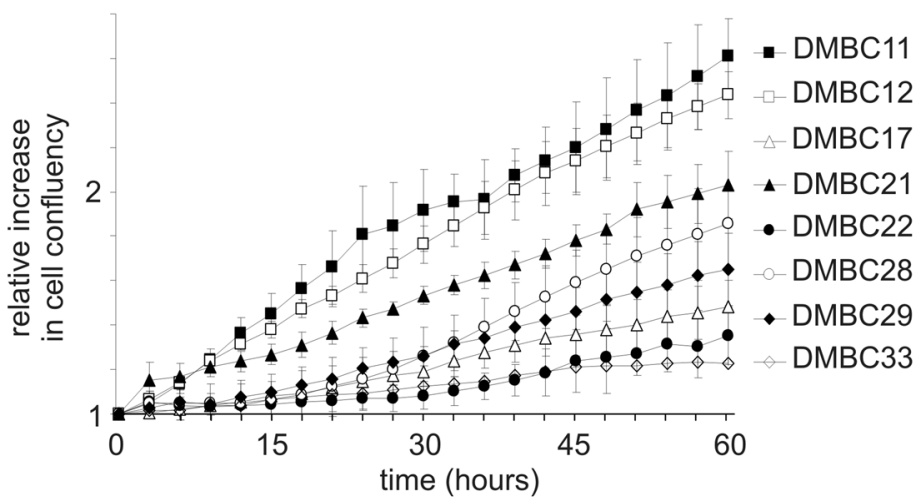

C

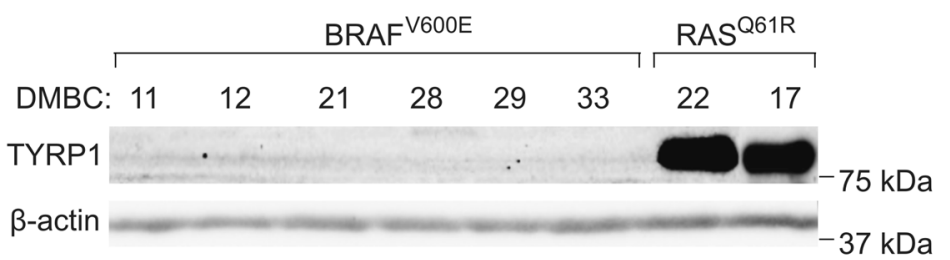

B

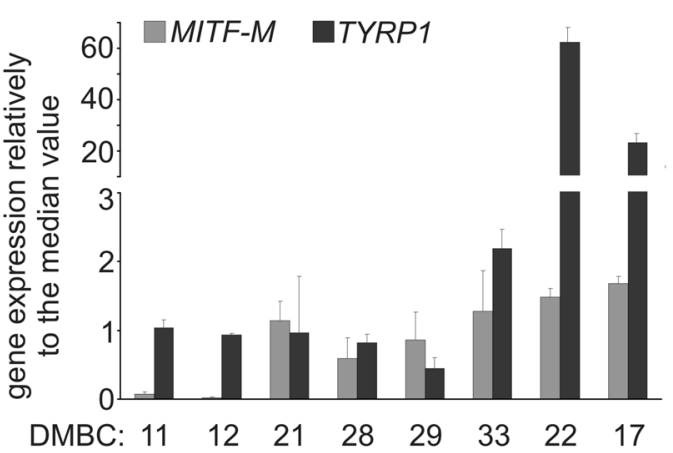

D

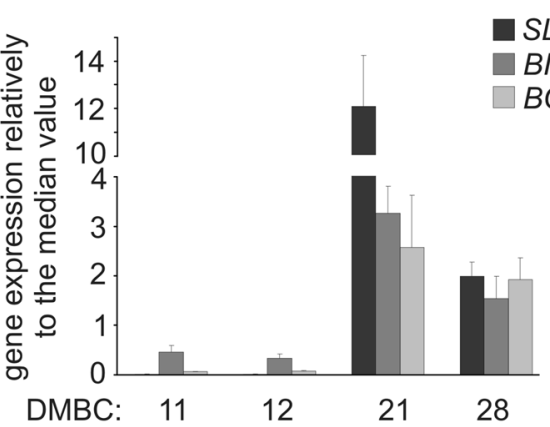

Fig. 1 TYRP1 transcript level in patient-derived melanoma cell lines is MITF-M-independent and not related to proliferation rate. a Proliferation time-courses. Cell proliferation was monitored by analyzing the occupied area of cell images over time using IncuCyte, and it is shown as an increase in cell confluency relative to the confluency at time $0 . n=3 \mathbf{b}$ Expression of TYRP 1 and $M I T F-M$ was determined by qRT-PCR and normalized to the expression of a reference gene RPS17. Gene expression levels in each melanoma cell line are expressed relative to the median value of all eight cell lines. Bars rep- resent mean values $\pm \mathrm{SD}, n=3$. c Representative Western blot images showing basal levels of TYRP1 protein in tested melanoma cell lines. $\beta$-Actin was used as a loading control. d Expression of three MITFdependent genes, SLC45A2, BIRC7 and BCL2A1, was determined in two MITF-M ${ }^{\text {low }}$ and two MITF-M ${ }^{\text {high }}$ melanoma cell lines by qRTPCR and normalized to the expression of a reference gene RPS17. Gene expression levels in each melanoma cell line are expressed relative to the median value of all four cell lines. Bars represent mean values $\pm \mathrm{SD}, n=3$ 
well reflected at the protein level as TYRP1 protein was undetectable in $\mathrm{BRAF}^{\mathrm{V} 600 \mathrm{E}}$ melanoma cells, whereas for $\mathrm{RAS}^{\mathrm{Q} 61 \mathrm{R}}$ cells a strong signal was obtained (Fig. 1c).

To verify whether only TYRPI expression was MITF$\mathrm{M}$-independent, the transcript levels of other genes, BIRC7, $B C L 2 A 1$ and SLC45A2, previously recognized as regulated by MITF-M, were assessed in MITF-M ${ }^{\text {low }}$ and MITF-M ${ }^{\text {high }}$ cell lines. Transcript levels of these genes in MITF-M ${ }^{\text {low }}$ cell lines were substantially lower than in MITF-M ${ }^{\text {high }}$ cell lines (Fig. 1d). These results indicate that among the genes whose expression was evaluated only TYRPI was MITF-M-independent.

\section{TYRP1 transcript level is similar in drug-naïve, vemurafenib- and trametinib-resistant melanoma cells, also those on 'drug holiday'}

First, we modeled the vemurafenib resistance in four $\mathrm{BRAF}^{\mathrm{V} 600 \mathrm{E}}$ melanoma cell lines. During development of resistance, the MITF-M protein level was substantially diminished in MITF-M ${ }^{\text {high }}$ cells and remained low/undetectable in MITF-M ${ }^{\text {low }}$ melanoma cells (Fig. 2a). TYRP1 protein could not be detected in vemurafenib-resistant cells, similarly as in their drug-naïve counterparts (Fig. 2a). Changes in MITF-M level were reflected in its activity shown as downregulation of three MITF-M-dependent genes, SLC45A2, BIRC7 and $B C L 2 A 1$ (Fig. 2b). On the contrary, TYRP1 transcript level was stable in vemurafenib-resistant cell lines regardless of changes in the MITF-M level (Fig. 2b). This further supports the notion that TYRPI expression is MITF-M-independent. Interestingly, when vemurafenib-resistant cells were subjected to drug removal ("drug holiday") for 10 days, MITF-M level and expression of all four tested genes remained unaffected (Fig. 2a, b). TYRP1 transcript levels, which were almost the same in drug-naïve, vemurafenib-resistant and on-drug-holiday $\mathrm{BRAF}^{\mathrm{V} 600 \mathrm{E}}$ melanoma cells, were not markedly altered also in cells only shortly exposed to vemurafenib (Fig. 2c). Similarly, short treatment with trametinib, a MEK1/2 inhibitor, did not affect substantially the transcript level of TYRP1 in MITF-M ${ }^{\text {high }}$ cell lines, DMBC21 and DMBC28 (Fig. 2d). Reduction of MITF expression observed after development of resistance to trametinib in those cell lines was even potentiated after drug cessation (Fig. 2e). While this was associated with a significant downregulation of SLC45A2, BIRC7 and BCL2AI (Fig. 2f), TYRP1 transcript level was not significantly altered (Fig. 2f).

\section{TYRP1 expression remains stable in the majority of melanomas during development of resistance to $\mathrm{BRAF}^{\mathrm{V} 600}$ and MEK1/2 inhibitors}

TYRP1 mRNA levels in melanomas from patients who developed resistance to targeted therapeutics were examined using publicly available data sets. The majority of relapsed melanomas did not show any evidence of TYRP1 transcript loss (Fig. 3). Among seven patients who developed resistance to vemurafenib only one exerted reduced TYRPI expression in three out of four relapsed specimens. Among 24 patients treated with dabrafenib, another $\mathrm{BRAF}^{\mathrm{V} 600}$ inhibitor, the development of resistance could be linked with reduced TYRP 1 expression only in 3 patients that relapsed, when compared with the pretreatment specimens from the same patients. In other relapsed specimens it was either markedly increased ( 2 specimens) or remained unchanged (19 specimens). Similar trend was observed when TYRP1 transcript level was analyzed in samples from patients treated with a combination of dabrafenib and trametinib. Among 17 patients, diminution of TYRPI expression was found only in 4 patient specimens, while TYRP1 mRNA level increased in 6 samples and remained unaltered in other 7 specimens (Fig. 3). This analysis further supports the notion that the TYRP1 transcript level is stable also in clinical samples of relapsed melanomas that are resistant to $\mathrm{BRAF}^{\mathrm{V} 600}$ and $\mathrm{BRAF}^{\mathrm{V} 600}+\mathrm{MEK} 1 / 2$ inhibitors.

\section{Discussion}

Elevated TYRP1 mRNA levels were detected in metastatic melanoma biopsies $[3,16]$, and correlated with poor overall patient survival [10-12, 28]. Unlike TYRP1 mRNA, TYRP1 protein did not correlate with overall survival, and TYRP1 protein was not detected in half of the melanoma samples expressing the TYRP1 transcript [11, 12, 28].

Our results indicate that TYRP1 protein is not detectable in the majority of samples that express TYRPl at the transcript level. Moreover, mutation leading to $\mathrm{BRAF}^{\mathrm{V} 600 \mathrm{E}}$ might be connected with a medium level of TYRP1 mRNA and undetectable TYRP1 protein, whereas mutation leading to either NRAS ${ }^{\mathrm{Q} 61 \mathrm{R}}$ or HRAS ${ }^{\mathrm{Q} 61 \mathrm{R}}$ might be associated with high levels of TYRP1 transcript and protein. It would be interesting to check whether there is any correlation between the molecular type of melanoma ( $\mathrm{m} B R A F, \mathrm{~m} R A S, \mathrm{~m} N F 1$, or triple wild type) [38] and TYRPI expression.

The high level of TYRP1 mRNA promotes proliferation and tumor growth irrespective of the protein level [17]. In our study, there was no strong association between TYRP1 mRNA level and cell proliferation rate. Melanoma cell lines with the highest proliferation rate were among lines expressing TYRP1 transcript at a medium level, whereas those with the highest expression of TYRPI at the transcript and protein levels exerted one of the lowest proliferation rates. However, our results are in agreement with the findings of Gilot et al. [17] when cells lacking detectable TYRP1 protein and expressing TYRP1 mRNA at the level below the median value are exclusively considered. This suggests that 
A

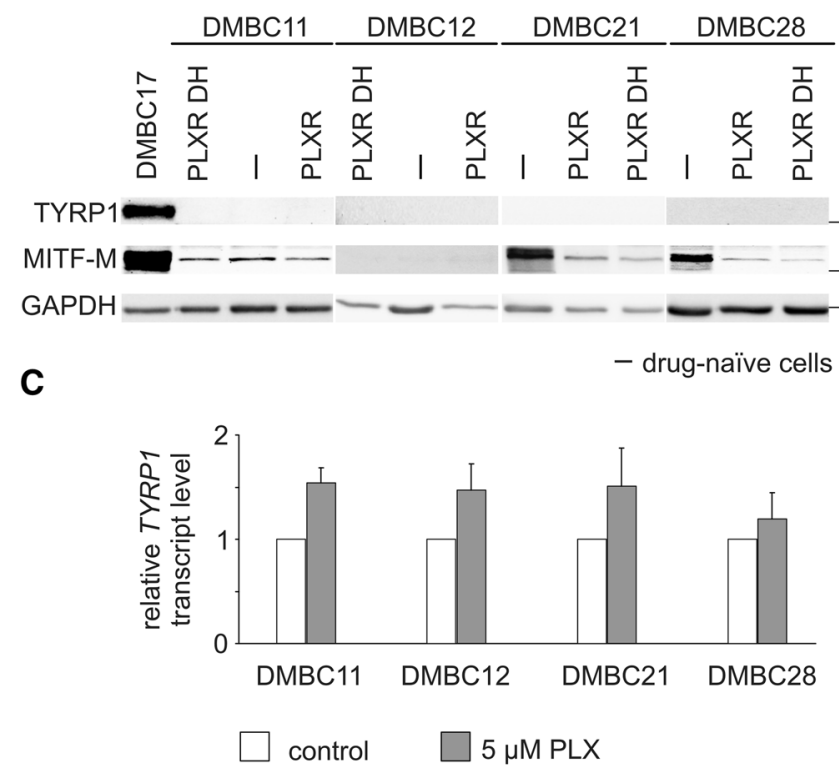

D

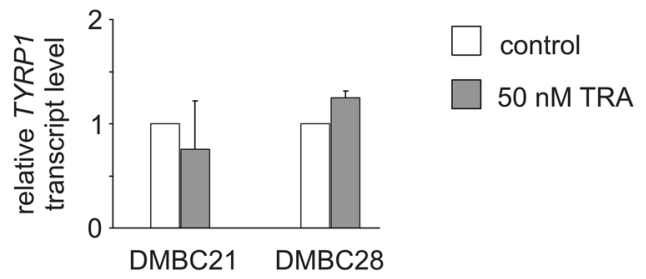

E

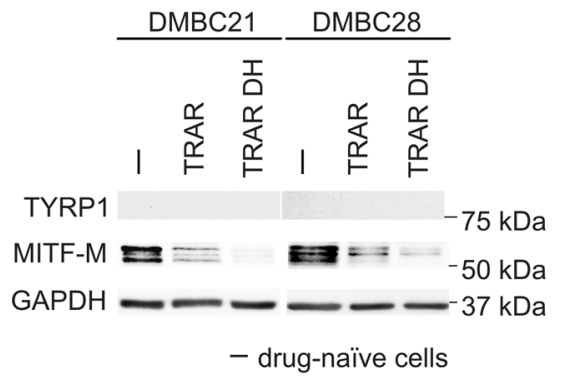

Fig. 2 TYRP1 expression is unaltered at the mRNA level and remains undetectable at the protein level during development of resistance to vemurafenib (PLX) and trametinib (TRA) in $\mathrm{BRAF}^{\mathrm{V} 600 \mathrm{E}}$ melanoma cells regardless of changes in the MITF-M level. a Representative Western blot images showing comparison of TYRP1 and MITF-M protein levels in drug-naïve (-) vs. vemurafenib-resistant (PLXR) cell lines. The levels of TYRP1 and MITF-M in vemurafenib-resistant melanoma cells subjected to drug discontinuation ('drug holiday'; PLXR DH) are included. GAPDH was used as a loading control. DMBC17 cell lysate was used in parallel as a positive control for TYRP1 and MITF-M staining. b Comparison of expression of TYRP1, SLC45A2, BIRC7 and BCL2A1 in vemurafenib-resistant $\mathrm{BRAF}^{\mathrm{V} 600 \mathrm{E}}$ melanoma cell lines either exposed to drug or after drug discontinuation ('drug holiday'), relative to expression in their drugnaïve counterparts. Bars represent mean values $\pm \mathrm{SD}, n=3,{ }^{*} p \leq 0.05$. c Expression of TYRP1 at the mRNA level in drug-naïve melanoma
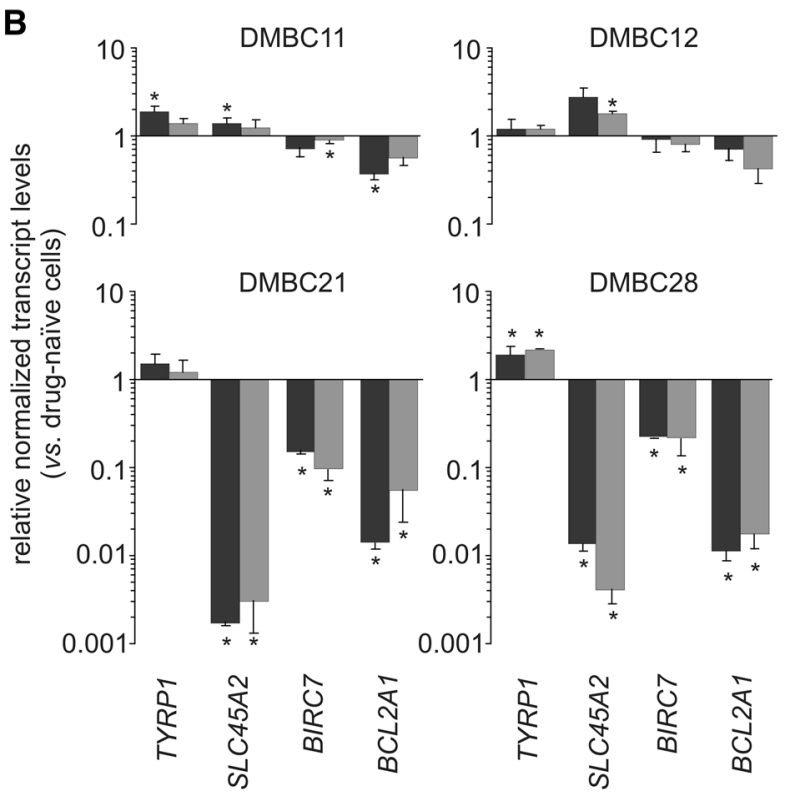

PLXR PLXR DH

$\mathbf{F}$

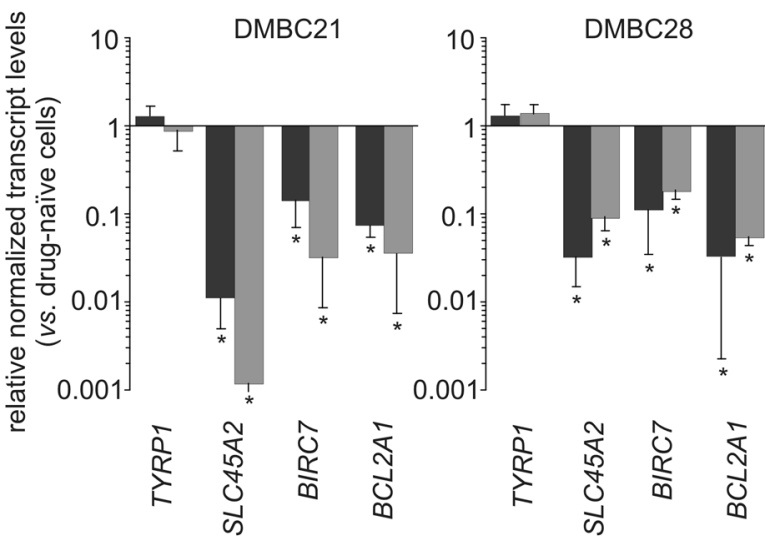

TRAR TRAR DH

cells exposed to vemurafenib for $22 \mathrm{~h}$, relative to its expression in untreated cells. Bars represent mean values $\pm \mathrm{SD}, n=3$. d Expression of TYRP1 at the mRNA level in drug-naïve melanoma cells exposed to trametinib for $22 \mathrm{~h}$, relative to its expression in control cells. Bars represent mean values $\pm \mathrm{SD}, n=3$. e Representative Western blot images showing comparison of TYRP1 and MITF-M protein levels in drug-naïve (-) vs. trametinib-resistant (TRAR) cell lines, also subjected to drug discontinuation ('drug holiday'; TRAR DH) are included. GAPDH was used as a loading control. f Comparison of expression of TYRP1, SLC45A2, BIRC7 and BCL2A1 in TRAR cell lines either exposed to drug or after drug discontinuation (TRAR $\mathrm{DH})$, relative to expression in their drug-naïve counterparts. Bars represent mean values $\pm \mathrm{SD}, n=3$. Expression of indicated genes in $\mathbf{b}-\mathbf{d}$ and $\mathbf{f}$ was assessed by qRT-PCR and normalized to the expression of a reference gene RPS17 

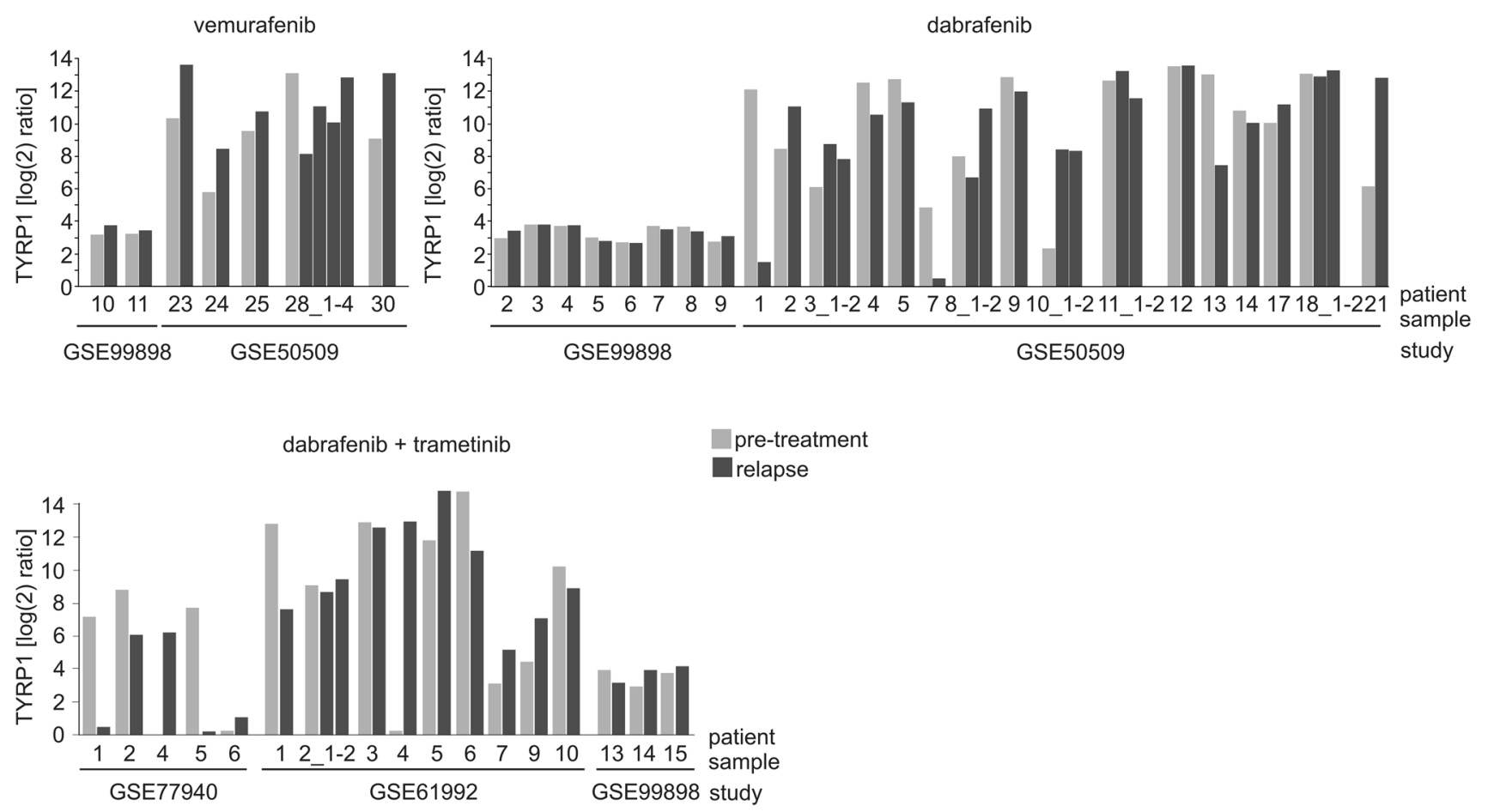

Fig. 3 TYRP1 expression at the mRNA level is not markedly changed in the majority of the relapsed patients who developed resistance to $\mathrm{BRAF}^{\mathrm{V} 600}$ inhibitors, vemurafenib or dabrafenib, or combined $\mathrm{BRAF}^{\mathrm{V} 600}$ and MEK1/2 inhibitors, dabrafenib and trametinib, in comparison to its expression before treatment. Data showing TYRP1 mRNA levels in paired melanoma specimens, pretreatment and post-

the proliferation rate may be connected with TYRP1 mRNA level within this narrow range of TYRP1 expression.

The level of TYRP1 mRNA is a consequence of the transcriptional and post-transcriptional regulation [13-15, 18, $31,41,43]$. It is possible that regulation of TYRP1 expression in MITF-M ${ }^{\text {low }}$ melanoma cells is stabilized by other transcription factors or regulatory mechanisms. The singlenucleotide polymorphism rs683 located in the 3'-untranslated region of TYRP 1 was connected with reduced binding of miR-155 and its mRNA decay activity [10,31]. miRNA155 expression is down-regulated in the majority of melanoma cell lines in comparison to melanocytes [30]. Therefore, influence of miR-155 on the TYRP1 transcript stability might be diminished during melanoma development. It has also been shown that miR-16, which interplays with miR155, participates in the stabilization of TYRP1 mRNA [36].

TYRP1 expression is MITF-M-dependent in melanocytes [14]. A significant correlation between TYRP1 mRNA level and MITF level was found also in a subset of melanoma cell lines $[11,41]$. Our results are contradictory to these findings as: (i) TYRPl expression was similar in MITF-M ${ }^{\text {low }}$ and MITF-M $M^{\text {high }}$ melanoma cells and (ii) MITF-M loss accompanying the development of drug resistance in MITF-M ${ }^{\text {high }}$ cells, did not influence TYRPI relapse, are presented as light gray columns and dark gray columns, respectively. For some patients, more than one relapsed samples were examined. Results are expressed as $\log _{2}$ ratios normalized to the mean intensity of pretreatment specimens. Data were obtained from NCBI GEO (https://www.ncbi.nlm.nih.gov/geo/), and study identifiers are indicated.

expression. Interestingly, our results are consonant with an earlier study showing lack of significant changes in TYRPI expression upon Mitf-transfection of Mitf ${ }^{\text {low }}$ SKMEL-28 melanoma cells [27]. The expression of other genes, BCL2A1, SLC45A2 and BIRC7, was markedly upregulated upon Mitf-transfection in that study [27], indicating that only the TYRPl promoter was non-responsive to functional exogenous MITF.

The role of RNAs as endogenous miR sponges has been demonstrated [2, 7, 19, 25, 29, 39]. TYRP1 mRNA on its non-canonical miRNA response elements can sequester miR-16 and de-repress targets of miR-16 [17]. For the first time, we have shown that the TYRP1 transcript level is not affected during both acute response and development of resistance to vemurafenib and trametinib, which suggests that the role of TYRP1 mRNA as endogenous 'miR sponge' is preserved in resistant cells. Our findings are supported by the analysis of publicly available data on TYRP1 expression in melanoma samples from patients before treatment and at the time of tumor progression due to development of resistance to targeted therapeutics. This analysis confirms stable expression of TYRPI in melanoma cells irrespective of their sensitivity to $\mathrm{BRAF}^{\mathrm{V} 600}$ and MEK1/2 inhibitors. 


\section{Conclusion}

A 'sponge' activity of TYRP1 transcript in melanoma cells resistant to $\mathrm{BRAF}^{\mathrm{V} 600 \mathrm{E}}$ and MEK1/2 inhibitors was not considered until now. Our results proving that TYRPI expression is MITF-M-independent in melanoma cells suggest that regardless of the mechanisms that are responsible for the stable level of TYRP1 mRNA in melanoma cells, therapies developed to terminate a sponge activity of TYRP1 transcript might be extended to patients that relapse with vemurafenib/trametinib-resistant disease.

Acknowledgements We thank Dr. Malgorzata Sztiller-Sikorska and Dr. Anna Gajos-Michniewicz for cell culture propagation, Prof. Markus Düchler for stimulating discussion and Ewa Lewandowska for excellent administrative and technical support.

Funding This work was financially supported by Grant 2014/15/B/ NZ7/00947 from National Science Centre (Poland).

\section{Compliance with ethical standards}

Conflict of interest The authors declare that they have no conflict of interest.

Open Access This article is distributed under the terms of the Creative Commons Attribution 4.0 International License (http://creativeco mmons.org/licenses/by/4.0/), which permits unrestricted use, distribution, and reproduction in any medium, provided you give appropriate credit to the original author(s) and the source, provide a link to the Creative Commons license, and indicate if changes were made.

\section{References}

1. Aida S, Sonobe Y, Tanimura H, Oikawa N, Yuhki M, Sakamoto H, Mizuno T (2017) MITF suppression improves the sensitivity of melanoma cells to a BRAF inhibitor. Cancer Lett 409:116-124

2. Babalola O, Mamalis A, Lev-Tov H, Jagdeo J (2013) The role of microRNAs in skin fibrosis. Arch Dermatol Res 305:763-776

3. Boissy RE, Sakai C, Zhao H, Kobayashi T, Hearing VJ (1998) Human tyrosinase related protein-1 (TRP-1) does not function as a DHICA oxidase activity in contrast to murine TRP-1. Exp Dermatol 7:198-204

4. Bolander A, Agnarsdóttir M, Strömberg S, Ponten F, Hesselius P, Uhlen M, Berggvist M (2008) The protein expression of TRP-1 and galectin-1 in cutaneous malignant melanomas. Cancer Genom Proteom 5:293-300

5. Carreira S, Goodall J, Denat L, Rodriguez M, Nuciforo P, Hoek KS, Testori A, Larue L, Goding CR (2006) Mitf regulation of Dia1 controls melanoma proliferation and invasiveness. Genes Dev 20:3426-3439

6. Cheli Y, Ohanna M, Ballotti R, Bertolotto C (2010) Fifteen-year quest for microphthalmia-associated transcription factor target genes. Pigment Cell Melanoma Res 23:27-40

7. Chi SW, Hannon GJ, Darnell GB (2012) An alternative mode of microRNA target recognition. Nat Struct Mol Biol 19:321-327

8. Czyz M, Sztiller-Sikorska M, Gajos-Michniewicz A, Osrodek M, Hartman ML (2019) Plasticity of drug-naïve and vemurafenib- or trametinib-resistant melanoma cells in execution of differentiation/pigmentation program. J Oncol 2019:1697913

9. Dynek JN, Chan SM, Liu J, Zha J, Fairbrother WJ, Vucic D (2008) Microphthalmia-associated transcription factor is a critical transcriptional regulator of melanoma inhibitor of apoptosis in melanomas. Cancer Res 68:3124-3132

10. El Hajj P, Gilot D, Migault M, Theunis A, Van Kempen LC, Salés F, Fayyad-Kazan H, Badran B, Larsimont D, Awada A, Bachelot L, Galibert MD, Ghanem G, Journe F (2015) SNPs at miR-155 binding sites of TYRP1 explain discrepancy between mRNA and protein and refine TYRP1 prognostic value in melanoma. Br J Cancer 113:91-98

11. El Hajj P, Journe F, Wiedig M, Laios I, Salès F, Galibert MD, Van Kempen LC, Spatz A, Badran B, Larsimont D, Awada A, Ghanem G (2013) Tyrosinase-related protein 1 mRNA expression in lymph node metastases predicts overall survival in high-risk melanoma patients. Br J Cancer 108:1641-1647

12. Falkenius J, Lundeberg J, Johansson H, Tuominen R, FrostvikStolt M, Hansson J, Egyhazi Brage S (2013) High expression of glycolytic and pigment proteins is associated with worse clinical outcome in stage III melanoma. Melanoma Res 23:452-460

13. Fang D, Setaluri V (1999) Role of microphthalmia transcription factor in regulation of melanocyte differentiation marker TRP-1. Biochem Biophys Res Commun 256:657-663

14. Fang D, Tsuji Y, Setaluri V (2002) Selective down-regulation of tyrosinase family gene TYRP1 by inhibition of the activity of melanocyte transcription factor, MITF. Nucleic Acids Res 30:3096-3106

15. Galibert MD, Yavuzer U, Dexter TJ, Goding CR (1999) Pax3 and regulation of the melanocyte-specific tyrosinase-related protein-1 promoter. J Biol Chem 274:26894-26900

16. Ghanem G, Journe F (2011) Tyrosinase related protein 1 (TYRP1/ gp75) in human cutaneous melanoma. Mol Oncol 5:150-155

17. Gilot D, Migault M, Bachelot L, Journé F, Rogiers A, DonnouFournet E, Mogha A, Mouchet N, Pinel-Marie ML, Mari B, Montier T, Corre S, Gautron S, Rambow F, El Hajj P, Ben Jouira R, Tartare-Deckert S, Marine JC, Felden B, Ghanem G, Galibert MD (2017) A non-coding function of TYRP1 mRNA promotes melanoma growth. Nat Cell Biol 19:1348-1357

18. Goding CR (2000) Mitf from neural crest to melanoma: signal transduction and transcription in the melanocyte lineage. Genes Dev 14:1712-1728

19. Hansen TB, Jensen TI, Clausen BH, Bramsen JB, Finsen B, Damgaard CK, Kjems J (2013) Natural RNA circles function as efficient microRNA sponges. Nature 495:384-388

20. Hartman ML, Czyz M (2015) MITF in melanoma: mechanisms behind its expression and activity. Cell Mol Life Sci 72:1249-1260

21. Hartman ML, Czyz M (2015) Pro-survival role of MITF in melanoma. J Invest Dermatol 135:352-358

22. Hartman ML, Rozanski M, Osrodek M, Zalesna I, Czyz M (2017) Vemurafenib and trametinib reduce expression of CTGF and IL-8 in V600EBRAF melanoma cells. Lab Invest 97:217-227

23. Hartman ML, Sztiller-Sikorska M, Czyz M (2019) Whole-exome sequencing reveals novel genetic variants associated with diverse phenotypes of melanoma cells. Mol Carcinogenesis 58:588-602

24. Hartman ML, Talar B, Noman MZ, Gajos-Michniewicz A, Chouaib S, Czyz M (2014) Gene expression profiling identifies microphthalmia-associated transcription factor (MITF) and Dickkopf-1 (DKK1) as regulators of microenvironment-driven alterations in melanoma phenotype. PLoS ONE 9:e95157

25. Hausser J, Zavolan M (2014) Identification and consequences of miRNA-target interactions-beyond repression of gene expression. Nat Rev Genet 15:599-612

26. Hoek KS, Eichhoff OM, Schlegel NC, Döbbeling U, Kobert N, Schaerer L, Hemmi S, Dummer R (2008) In vivo switching of 
human melanoma cells between proliferative and invasive states. Cancer Res 68:650-656

27. Hoek KS, Schlegel NC, Eichhoff OM, Widmer DS, Praetorius C, Einarsson SO, Valgeirsdottir S, Bergsteinsdottir K, Schepsky A, Dummer R, Steingrimsson E (2008) Novel MITF targets identified using a two-step DNA microarray strategy. Pigment Cell Melanoma Res 21:665-676

28. Journe F, Boufker H, Van Kempen L, Galibert MD, Wiedig M, Salès F, Theunis A, Nonclercq D, Frau A, Laurent G, Awada A, Ghanem G (2011) TYRP1 mRNA expression in melanoma metastases correlates with clinical outcome. Br J Cancer 105:1726-1732

29. Kim D, Sung YM, Park J, Kim S, Kim J, Park J, Ha H, Bae JY, Kim S, Baek D (2016) General rules for functional microRNA targeting. Nat Genet 48:1517-1526

30. Levati L, Alvino E, Pagani E, Arcelli D, Caporaso P, Bondanza S, Di Leva G, Ferracin M, Volinia S, Bonmassar E, Croce CM, D'Afri S (2009) Altered expression of selected microRNAs in melanoma: antiproliferative and proapoptotic activity of miRNA155. Int J Oncol 35:393-400

31. Li J, Liu Y, Xin X, Kim TS, Cabeza EA, Ren J, Nielsen R, Wrana JL, Zhang Z (2012) Evidence for positive selection on a number of MicroRNA regulatory interactions during recent human evolution. PLoS Genet 8:e1002578

32. McGill GG, Horstmann M, Widlund HR, Du J, Motyckova G, Nishimura EK, Lin YL, Ramaswamy S, Avery W, Ding HF, Jordan SA, Jackson IJ, Korsmeyer SJ, Golub TR, Fisher DE (2002) Bcl2 regulation by the melanocyte master regulator Mitf modulates lineage survival and melanoma cell viability. Cell 109:707-718

33. Murisier F, Guichard S, Beermann F (2006) A conserved transcriptional enhancer that specifies Tyrp1 expression to melanocytes. Dev Biol 298:644-655

34. Osrodek M, Hartman ML, Czyz M (2019) Physiologically relevant oxygen concentration $\left(6 \% \mathrm{O}_{2}\right)$ as an important component of the microenvironment impacting melanoma phenotype and melanoma response to targeted therapeutics in vitro. Int J Mol Sci. https:// doi.org/10.3390/ijms20174203

35. Rose AA, Annis MG, Frederick DT, Biondini M, Dong Z, Kwong L, Chin L, Keler T, Hawthorne T, Watson IR, Flaherty KT, Siegel PM (2016) MAPK pathway inhibitors sensitize BRAF-mutant melanoma to an antibody-drug conjugate targeting GPNMB. Clin Cancer Res 22:6088-6098

36. Soengas MS, Hernando E (2017) TYRP1 mRNA goes fishing for miRNAs in melanoma. Nat Cell Biol 19:1311-1312

37. Sztiller-Sikorska M, Koprowska K, Jakubowska J, Zalesna I, Stasiak M, Duechler M, Czyz ME (2012) Sphere formation and self-renewal capacity of melanoma cells is affected by the microenvironment. Melanoma Res 22:215-224

38. The Cancer Genome Atlas Network (2015) Genomic classification of cutaneous melanoma. Cell 161:1681-1696

39. Thomson DW, Dinger ME (2016) Endogenous microRNA sponges: evidence and controversy. Nat Rev Genet 17:272-283

40. Tsoi J, Robert L, Paraiso K, Galvan C, Sheu KM, Lay J, Wong DJL, Atefi M, Shirazi R, Wang X, Braas D, Grasso CS, Palaskas N, Ribas A, Graeber TG (2018) Multi-stage differentiation defines melanoma subtypes with differential vulnerability to drug-induced iron-dependent oxidative stress. Cancer Cell 33:890-904

41. Vachtenheim J, Novotna H, Ghanem G (2001) Transcriptional repression of the microphthalmia gene in melanoma cells correlates with the unresponsiveness of target genes to ectopic microphthalmia-associated transcription factor. J Invest Dermatol 117:1505-1511

42. Widlund HR, Fisher DE (2003) Microphthalamia-associated transcription factor: a critical regulator of pigment cell development and survival. Oncogene 22:3035-3041

43. Wozniak M, Mielczarek A, Czyz M (2016) miRNAs in melanoma: tumor suppressors and oncogenes with prognostic potential. Curr Med Chem 23:3136-3153

44. Yamaguchi Y, Hearing VJ (2009) Physiological factors that regulate skin pigmentation. BioFactors 35:193-199

45. Yamaguchi Y, Takahashi K, Zmudzka BZ, Kornhauser A, Miller SA, Tadokoro T, Berens W, Beer JZ, Hearing VJ (2006) Human skin responses to UV radiation: pigment in the upper epidermis protects against DNA damage in the lower epidermis and facilitates apoptosis. FASEB J 20:1486-1488

Publisher's Note Springer Nature remains neutral with regard to jurisdictional claims in published maps and institutional affiliations. 